Cad.Est.Ling., Campinas, (44):291-299, Jan./Jun. 2003

\title{
MULHER BRASILEIRA NA POLÍTICA: PRECONCEITOS E EVOLUÇÕES - REPRESENTAÇÕES NA MÍDIA
}

\author{
ASTRID NILSSON SGARBIERI \\ (PUC/Campinas)
}

\begin{abstract}
This article analyses some processes of reference in the representation of women in politics in the media. The results point to a close relationship between discourse and social identity as well as that reference is a contextualized activity related to socially constructed ideologies.
\end{abstract}

As mulheres brasileiras foram, durante muito tempo, educadas para as atividades do lar e, dessa forma, quando, mesmo qualificadas, buscam espaços na economia formal ainda enfrentam preconceitos e discriminação. Embora, atualmente, representem $40,3 \%$ da força de trabalho, um percentual significativo delas ainda atua no setor informal.

Estatísticas recentes comprovam que para executar a mesma função, as mulheres que em 1983 ganhavam 45\% do salário dos homens, em 2002 ganham até 65\% desse salário. Uma das razões para tal mudança ou evolução, de acordo com estudos recentes, é em função do aumento do nível de escolaridade das mulheres - especialmente o nível universitário. Entretanto, a combinação entre mais baixos salários e responsabilidades maiores nas famílias chefiadas pelas mulheres tem levado à maior vulnerabilidade social desse segmento da população.

No cenário político torna-se importante lembrar que, de acordo com a Constituição Brasileira de 1891, às mulheres era vetado o direito ao voto. Em 1927, no estado do Rio Grande do Norte, um político - Juvenal Lamartine de Faria - fez mudanças no Código Eleitoral de seu Estado e invocou alterações na Constituição Federal para que as mulheres pudessem exercer seus direitos políticos. Foi em 1929 que, no município de Lajes, no Rio Grande no Norte, Alzira Soriano de Souza foi a primeira prefeita eleita não só no Brasil, mas também na América Latina. Entretanto, com a vitória da Revolução de 1932, Alzira deixou a prefeitura.

O direito de voto das mulheres veio por decreto do presidente Getúlio Vargas, em 24 de fevereiro de 1932, uma vitória que, na época, soava conservadoramente. Os temas defendidos pelas feministas dos anos 30 eram: os interesses das mulheres trabalhadoras; a necessidade de se instituir educação em colégios mistos; a mudança da legislação que reconhecia como incapaz a mulher casada; a política voltada às crianças abandonadas e a emancipação econômica das mulheres. Com a ditadura Vargas (19371945), porém, a articulação dessas reivindicações foi diluída. 
As mulheres passaram a votar, efetivamente, em 1946, e uma retomada do ativismo feminino aconteceu no final dos anos 1970 e 1980, com movimentos sociais organizados em torno de novos temas, seguindo orientações das organizações feministas mundiais.

A relação entre linguagem, pensamento e mundo instala-se no discurso. Tal relação, porém, está longe de ser totalmente explícita, mas permite observar e analisar, em diferentes momentos e de formas diferentes, a ideologia dos falantes ou de quem escreve através do discurso. Relevante, também, é a relação discurso/identidade social, uma vez que esta é formada ao longo do tempo, por meio de processos inconscientes em andamento, que estão em constante evolução. A questão da identidade está relacionada ao caráter da mudança na modernidade e, em particular, à globalização que exerce um forte impacto sobre a identidade cultural. As sociedades modernas têm um caráter específico, o que nos remete ao pensamento de Marx sobre modernidade:

É o permanente revolucionar da produção, o abalar ininterrupto de todas as condições sociais no ar..., a incerteza e o movimento eternos.... Todas as relações fixas e congeladas, com seu cortejo de vetustas representações e concepções, são dissolvidas, todas as relações recémformadas envelhecem antes de poderem ossificar-se. Tudo que é sólido se desmancha (Marx e Engels, 1973:7).

Os aspectos estudados sobre as mudanças na representação da mulher na mídia demonstram, com clareza, que a sociedade brasileira faz parte das sociedades modernas que são, por definição, sociedades em mudança constante, rápida e permanente. Esta é a principal distinção entre as sociedades "tradicionais" e as "modernas". Anthony Giddens (1991:37) argumenta que:

Nas sociedades tradicionais, o passado é venerado e os símbolos são valorizados porque contêm e perpetuam a experiência de gerações. A tradição é um meio de lidar com o tempo e o espaço inserindo qualquer atividade ou experiência particular na continuidade do passado, presente e futuro, os quais, por sua vez, são estruturados por práticas sociais recorrentes. (tradução da autora).

No presente trabalho é importante lembrar que os aspectos estudados sobre as mudanças na representação da mulher na mídia demonstram, com bastante clareza, que a sociedade brasileira se insere num mundo globalizado, moderno e que está sempre passando por mudanças. No caso da mulher, é interessante lembrar a mudança na sociedade brasileira que em 1929 elege a primeira mulher prefeita, Alzira Soriano de Souza, e, em 1994, elege, pela primeira vez, uma mulher governadora, Roseana Sarney, que se reelege, com folga, em 1998.

A revista Veja, em número especial Mulher - a grande mudança no Brasil, de setembro de 1994, pode ser considerada um marco nas representações da mulher na mídia por apresentar algumas mudanças e evoluções da mulher em nossa sociedade. $\mathrm{Na}$ revista citada, o artigo Nas franjas do poder enfatiza algumas evoluções na sociedade, ao mencionar que, em 1933, a médica Carlota Pereira Queiroz, paulista de 42 anos, solteira, militante, é a primeira deputada a tomar lugar na Câmara. O artigo menciona, 
também, Zélia Cardozo de Mello como um divisor de águas quando, em 1991, foi nomeada a primeira ministra da fazenda no Brasil.

A teoria da identidade social está intimamente ligada a laços grupais. Nesse contexto, entendemos sociedade, segundo Tajfel (1978), como uma estrutura composta de grupos que se relacionam entre si, tendo como fundamento a relação de poder e status. Podemos afirmar, portanto, que a estrutura da sociedade influi diretamente na formação da identidade.

A relação de poder e status entre grupos está ligada à identidade social, que permite ao grupo dominante na sociedade, por deter o poder e o status, impor valores e ideologias que, por sua vez, servem para legitimar e perpetuar o status quo. Os dois exemplos acima citados ilustram, com clareza, alguns aspectos de mudança na sociedade brasileira quanto à identidade social da mulher (as primeiras mulheres: uma deputada e outra ministra da fazenda).

Vale lembrar que os indivíduos nascem já inseridos numa estrutura e, simplesmente em função do sexo ou classe social, entre outros itens, são "colocados" num ou noutro grupo. Dessa forma, adquirem as categorias sociais definitivas dos grupos aos quais pertencem e que podem ter valores sociais positivos ou negativos. Os membros dos grupos dominantes e de status superior passam a ter identidade social positiva e maior grau de auto-estima. Da mesma forma os membros de status inferior ou de grupos subordinados têm ou adquirem identidade social menos positiva e menor auto-estima. (vide exemplo 17, mais à frente, que menciona, claramente, o grupo social ao qual Roseana pertence).

A conscientização da mudança de status da mulher na sociedade, especialmente no Brasil, deve ser vista como um aspecto histórico e culturalmente específico, embora ainda em nossos dias possamos encontrar a mulher eterna feminina que persiste através dos tempos e a nova mulher que evolui e muda com o passar do tempo e sob a influência do mesmo. Essa conscientização é muito importante para que a mulher venha a evoluir e conquistar espaços num mercado de trabalho cada vez mais competitivo e meritocrático. Tal mudança pode ser observada lingüisticamente de diferentes maneiras e em momentos distintos, como podemos observar em alguns exemplos que aparecem na Revista Época de 13 de março de 2000:

(1) Confiantes e mais exigentes, elas ocupam espaços na cena política, disputam o mercado de trabalho com os homens e arrombam a porta do Judiciário (p.58).

(2) Prefeitas de pulso firme.Elas são vistas como mais honestas e dedicadas (p.61).

(3) Tinha todas as credenciais para a derrota: mulher, pobre e nordestina - a biografia de Luiza Erundina. Mas não se livrou da fuzilaria. (p.61).

(4) Na próxima encarnação quero nascer homem e careca. (p.61)

(5) Foi o presidente quem deu espaço para mulher mostrar o que sabe aqui em Brasília (p.60)

(6) A ministra é muito inteligente, apesar de ser mulher, disse o presidente da Fiesp ao referir-se a Ministra do Trabalho, Dorothea Werneck. (p.62)

(7) Mulheres se libertam, mas foram contempladas com a vida estressada, desprovida de lazer e prazer e as trabalhadoras deixam as queixas de lado e partem para a competição frontal com os homens. Incorporam a dupla jornada. (p.63) 
Nos exemplos citados podemos observar que as mulheres têm que lutar e, muitas vezes, enfrentam sacrifícios para conquistar ou estabelecer espaços não só no mercado de trabalho, mas também na sociedade, os quais já deveriam ser direitos naturais.

\section{MÍDIA E CONHECIMENTO}

Neste trabalho parto da premissa que a mídia não só incorpora elementos da realidade, mas também modula, re-dimensiona e re-cria essa mesma realidade podendo ou não reforçá-la. A notícia, portanto, não é apenas um fenômeno natural que emerge de fatos da vida real, mas é social e culturalmente determinada uma vez que ela é produzida por pessoas que fazem parte de uma rede de relações sociais revelando assim não só as próprias ideologias, mas também as do grupo social a que pertencem.

As notícias representam importante papel social, político e educacional, permitindo que as pessoas façam ligações, expliquem, interpretem e compreendam como os assuntos relatados na mídia estão intimamente ligados com a sociedade e a cultura a que pertencem. As notícias ou "eventos" para serem relatados precisam se "adequar" a um sistema de prioridades que é estabelecido pelas instituições que as criam.

A mídia, de um modo geral, é de vital importância para a compreensão de diferentes aspectos da produção de notícias e sua respectiva compreensão. De fundamental importância para os jornalistas é o conhecimento de mundo, de um modo geral, e especialmente o conhecimento de acontecimentos mais recentes.

Sabemos que para compreendermos, tanto uma simples história infantil bem como detalhes de notícias que são produzidas, é necessário uma grande quantidade de conhecimento prévio. A teoria dos modelos mentais (representações mentais de eventos) tem mostrado como o conhecimento específico utilizado para o processamento do discurso pode estar relacionado ao conhecimento geral, o que irá fazer a ligação entre conhecimento e discurso. (van Dijk 1998:5)

É importante lembrar que o conhecimento está intimamente ligado a crenças, valores, opiniões, atitudes e ideologias dentre outros (van Dijk, 1998). Até mesmo uma leitura rápida das manchetes num jornal ou numa revista irá ativar o que acabamos de mencionar.

Na revista Época, de 13 de março de 2000, em artigos especiais que abordam diferentes aspectos da Mulher, uma das manchetes é:

(8) Sinhazinha redimida a primeira governadora da História do Brasil e herdeira de um dos clãs mais poderosos do Nordeste é a carta da vez no baralho da sucessão presidencial.

O texto enfatiza, também, a importância e o poder da família Sarney, quando pessoas entrevistadas afirmam: Só sei onde mora o pai dela.....Roseana toma café da manhã,.... recebe colaboradores, dá entrevistas e despacha os assuntos de Estado na mansão do Pai. Na seqüência, o artigo ressalta a relação que Roseana mantém com o pai, embora a governadora afirme: "quem manda no governo sou eи e não o теи pai 
ou meu marido". O artigo finaliza com a seguinte observação: é a mulher mais importante no cenário político nacional, na virada do milênio.

No mesmo artigo, encontramos a seguinte referência à Roseana:

$$
\text { menina rica e deslumbrada que estão vendendo como estadista. }
$$

Outro exemplo, encontrado no jornal Folha de São Paulo, de 2 de dezembro de 2001:

(10) Pefelista se diz vítima de preconceito por ser bonitinha e mulher.

Os exemplos irão, certamente, ativar nosso conhecimento prévio da uma sociedade patriarcal, especialmente no nordeste do Brasil, onde há uma relação direta de dependência - o pai, um político conhecido e que exerce muito poder no Maranhão e Roseana,

(11) filha de uma oligarquia que há mais de três décadas manda num dos Estados mais atrasados e pobres do Brasil.

Sem um conhecimento prévio, a leitura dos textos apresentados não seria possível fazer a ligação de valores, opiniões, atitudes e ideologia conforme proposto por van Dijk (op.cit).

De um modo geral, as abordagens tradicionais nos estudos de ideologia enfatizam como esta pode afetar as diferentes formas discursivas e seus significados, bem como as estruturas discursivas podem contribuir para a formação e a transformação de ideologias. Lembramos, porém, que as ideologias estão presentes também quando os usuários de uma língua se engajam na construção de contextos bem como na interpretação de situações sociais.

Isto significa dizer que as ideologias podem influenciar a maneira como as atitudes sociais são expressas nas estruturas do discurso. A manifestação das ideologias pode ser observada em formas variadas, a saber: crenças ou valores expressos em diferentes níveis do discurso, como por exemplo: na sintaxe, na seleção lexical, na topicalização ou nas formas implícitas, dentre outras. Em outras palavras, a ideologia pode, direta ou indiretamente, afetar a produção e a interpretação do discurso (vide exemplos 11,12 e 13).

Seguindo o arcabouço teórico multidisciplinar proposto por van Dijk (2001) que define ideologia como uma forma especial de cognição social compartilhada por membros de um grupo social, pode-se afirmar que as ideologias são a base das representações sociais e das práticas de membros de um grupo, incluindo seus discursos, os quais servem, ao mesmo tempo, como um meio de produção e também de reprodução de ideologias. O estudo das ideologias deve, portanto, abranger o contexto e os processos sociocognitivos de produção e compreensão de diferentes discursos.

A teoria dos modelos mentais, segundo van Dijk (1998) tem mostrado como o conhecimento específico utilizado para o processamento do discurso pode estar 
relacionado ao conhecimento geral, o que irá fazer a ligação entre conhecimento e discurso.

Importante, também, para compreensão do discurso é a questão da referência que foi tradicionalmente entendida como a designação extensional de entidades do mundo extralingüístico, isto é, como etiquetagem apriorística que estabelece uma relação biunívoca entre linguagem e mundo. Atualmente, segundo Marcuschi (2000a,b), a referenciação está intimamente ligada à interpretação textual e contextual para quem referir não é etiquetar, nem apontar, nem relacionar, mas sim, agir colaborativamente na produção de orientações interpretativas, tornando-se, desta forma, um processo ou mesmo uma atividade que se constrói. Tal fato nos remete à noção de que todas nossas atividades sejam elas lingüísticas ou não são sempre contextualizadas, não dependendo de representações abstratas ou impositivas de um mundo a priori ou de um mundo explicitado objetivamente.

A referência é, pois, parte da realidade que é construída, mantida e alterada essencialmente pela forma como sócio-cognitivamente interagimos e compreendemos o mundo que nos cerca.

Segundo Koch (2002), numa concepção interacional de língua, o texto deve ser considerado como o próprio lugar de interação e os interlocutores, como sujeitos ativos que - dialogicamente - nele se constroem e são construídos. Desta forma, há lugar no texto para toda uma gama de implícitos, dos mais variados tipos, somente detectáveis quando se tem, como pano de fundo, o contexto sociocognitivo dos participantes da interação.

A seguir são apresentados alguns exemplos que ilustram o que foi mencionado. A revista Veja, de 14 de novembro de 2001, traz na capa a seguinte manchete:

(12) O fenômeno Roseana - os bastidores da campanha que levou a governadora do Maranhão ao segundo lugar nas pesquisas.

Observamos, agora, que não se trata mais da Sinhazinha redimida, mas do fenômeno. $\mathrm{O}$ artigo referente à manchete de capa cita:

(13) ... é filha de ex-presidente, com saúde frágil e um governo bem avaliado, vira estrela na corrida para o Planalto ao assumir o segundo lugar nas pesquisas eleitorais... sua sucessão é resultado direto de um trabalho de laboratório, uma vez que ela tem sido a única estrela na propaganda do PFL.

Pensando que referir não é etiquetar nem apontar, mas agir colaborativamente na produção de orientações interpretativas, cito alguns exemplos retirados do jornal $O$ Estado de São Paulo, de 20 de outubro de 2001, cuja manchete é: O poder da saia....primeiro nome feminino para assumir o Planalto...representante do sexo feminino... musa no processo do impeachment... sobrevivente de dez cirurgias...

O jornal Folha de São Paulo, de 11 de novembro de 2001 faz as seguintes referências à pré-candidata à Presidência:

(14) Roseana não chega ainda a ser a dama-de-ferro, mas poderá ser. 
O mesmo jornal, em edição de 14 de dezembro de 2001, refere-se à Roseana como:

(15) Mulher determinada e firme em suas decisões.

É interessante observar, também, como a mídia escrita apresenta a ex-précandidata após a descoberta das falcatruas sobre a utilização de verbas públicas, amplamente divulgada na mídia após a intervenção da Polícia Federal. A revista Época de 4 de março de 2002, traz na capa:

(16) Marido-problema contas em paraíso fiscal e outras provas da polícia contra o marido de Roseana Sarney.

O artigo que trata do assunto tem a seguinte manchete: A devassa contra Murad. Podemos observar que até esse momento a mídia questionava apenas a posição do marido da pré-candidata. A mesma revista, de 11 de março, já traz na capa a manchete:

(17) Segredos Revelados. Novos indícios de negócios suspeitos no inquérito que Roseana Sarney pediu para manter em sigilo.

A revista Veja traz, pela última vez, em 17 de abril, na capa, a manchete: Eles pensavam que o Brasil era o Maranhão, sendo que o artigo que trata do assunto traz a seguinte manchete: A candidata que virou pó e está fora do jogo da sucessão.

A revista Caros Amigos, de fevereiro de 2002, traz um artigo intitulado: Biografia (autorizada pelo povo do Maranhão) da candidata do PFL à Presidência da República: o nome dela é Roseana, mas pode chamar de Sarney. A mesma revista, após a renúncia da pré-candidata, publicou um livro inaugurando a série Histórias Inéditas, cujo título é:

(18) A candidata que virou picolé - e de limão.

A revista Veja de 6 de fevereiro de 2002 traz um ensaio assinado pelo conhecido articulista Roberto Pompeu de Camargo cujo título é: "A candidata e a cerveja". Fazendo um paralelo entre o anúncio da Brahma, a número 1, e Roseana, o autor escreve: "Sai a Brahma, entra Roseana Sarney".

O anúncio é o apoteótico casamento da política com a cevada e o lúpulo, da "loirinha" com a intenção de voto, do prazer e do barato com a urna". O ensaio termina lembrando a possibilidade da pré-candidata estar sendo vendida como sabão em pó, ao que o autor suscita a questão: "Não é como sabão em pó. É como cerveja".

Em editoriais do jornal $O$ Estado de São Paulo, dos dias 5, 7 e 8 de março de 2002, faz-se referência à Roseana como: "imatura e descontrolada" ou "vai longe o tempo em que o presidente era escolhido de acordo com as regras de promoção do Almanaque do Exército" (referindo-se a seu pai o ex-presidente José Sarney e a ditadura), e ainda: "A escolha de Sofia" referindo-se ao dilema imposto por Roseana ao PFL e que a classifica de "temperamental governadora". O último editorial refere-se à Roseana como "ré confessa". 
Mais próximo da data da renúncia da pré-candidata, a revista Veja, de 20 de março de 2002, traz na sessão Ponto de Vista, artigo assinado por Luiz Felipe de Alencastro cuja manchete é: "Roseana, Joana d'Arc e a política"

$\mathrm{O}$ artigo enfatiza que qualquer semelhança entre a santa guerreira e Roseana Sarney parece absolutamente fora de propósito.

Após a renúncia de Roseana em 14 de abril de 2002 a editora Casa Amarela publicou o livro de autoria de Palmério Dória, da série Caros Amigos - Histórias Inéditas com o seguinte título: "A candidata que virou picolé - e de limão".

\section{CONCLUSÃO}

Os exemplos citados neste trabalho apontam para uma relação entre discurso e identidade social, sendo que as mudanças na representação da mulher na mídia, especialmente na política, demonstram com bastante clareza que a sociedade brasileira se insere num mundo globalizado e que está sempre sendo atualizado.

Este estudo permite, também, afirmar segundo Koch (2002) e Marcuschi (2000a e 2000b) que nossas atividades, sejam elas lingüísticas ou não, são sempre contextualizadas, históricas e interacionais e não dependem de representações abstratas ou impositivas diretas de um mundo a priori ou de um mundo explicitado objetivamente.

Os exemplos apontam, também, para mudanças na sociedade brasileira num processo que podemos chamar de "on line", onde temos avanços, como por exemplo a pré-candidatura de Roseana, mas também, retrocessos como o Presidente "dar" espaço para mulher e ainda mais a diferença entre o salário pago ao homem e à mulher.

Quanto ao "fenômeno Roseana" julgo importante observar o poder da mídia na evolução/progressão da apresentação da pré-candidata. Em um primeiro momento referem-se a ela como "sinhazinha redimida, menina rica e deslumbrada, vítima de preconceito, filha de...".

Com o passar dos meses e a evolução das negociações para o lançamento oficial dos candidatos/as à Presidência, a mídia passa a referir-se a mesma pessoa como "fenômeno, dama da sucessão, musa, estrela", dentre outras expressões.

Vale lembrar que nos artigos analisados, apenas dois (Estado de São Paulo de 20 de outubro de 2001 e Veja de 14 de novembro de 2001) mencionam a saúde frágil da pré-candidata.

A partir de fevereiro de 2002 podemos observar que a mídia já ridiculariza a situação da candidata através do anúncio apoteótico no ensaio de Roberto Pompeu de Camargo, culminando com a publicação do livro "A candidata que virou picolé - e de limão”. Isto é, um picolé que, além de derreter, é amargo.

\section{BIBLIOGRAFIA}

DÓRIA, P.A. (2002). A candidata que virou picolé. Caros Amigos - série Histórias Inéditas. Casa Amarela. 
GIDDENS, A. (1991). Modernity and Self Identity: Self and Society in the Late Modern Age. Cambridge. Polity Press.

KOCH, I.V. (2002). Desvendando os segredos do Texto. Cortez Editora. São Paulo.

MARCUSCHI, L.A. (2000a). A articulação de orações no contexto da produção discursiva: uma tomada de posição. (mimeo)

. (2000b). Quando a referenciação é uma inferência. (mimeo).

MARX, K. \& ENGELS, F. (1973). The communist Manifesto. In Revolutions of 1848. Harmondsworth: Penguin Books.

TAJFEL, H. (1978). (ed.) Differentiation between Social Groups:Studies in the Social Psychology of Intergroup Relations. London: Academic Press.

TAJFEL, H. e Turner, J. (1979). An Integrative Theory of Intergroup Conflict. In W.H. Austin and S. Worchel (eds), The Social Psychology of Intergroup Relations. Montery, CA.: Brooks-Cole.

VAN DIJK, T.A. (1998). Ideology. A multidisciplinary Approach. London Sage. (2001). Knowledge and News (mimeo).

\section{Periódicos}

Caros Amigos - fevereiro de 2002

Época - 13 de março de 2000

Época - 04 de março de 2002

Época - 11 de março de 2002

Veja - edição especial - Setembro de 1994

Veja - 14 de novembro de 2001

Veja - 06 de fevereiro de 2002

Veja - 20 de março de 2002

Veja - 17 de abril de 2002

Jornais:

Folha de São Paulo-11 de novembro de 2001

Folha de São Paulo-14 de novembro de 2001

O Estado de São Paulo-20 de outubro de 2001

O Estado de São Paulo-5,7,8 de março de 2001 